\title{
Motor and Cognitive Developmental Profiles in Children With Down Syndrome
}

\author{
Hyo In Kim, MD, Seong Woo Kim, MD, Jiyong Kim, MD, Ha Ra Jeon, MD, Da Wa Jung, MD
}

Department of Physical Medicine and Rehabilitation, National Health Insurance Service Ilsan Hospital, Goyang, Korea

\begin{abstract}
Objective To investigate motor and cognitive developmental profiles and to evaluate the correlation between two developmental areas and assess the influencing factors of the developmental process in children with Down syndrome (DS).

Methods Seventy-eight children with DS participated in this study. The medical history was taken and motoric milestone achievements recorded. The Korean Wechsler Preschool and Primary Scale of Intelligence (K-WPPSI) and Bayley Scales of Infant Development-II (BSID-II) were administered. Subjects were divided into severe motor delay group (severe group) and typical motor delay group (typical group).

Results Children with DS follow the same sequence of motor development and generally displayed double times of acquisition of developmental milestones compared with healthy children. Furthermore, having surgery for associated complications showed negative influence to the motor development. Almost of all children with DS showed moderate degree of intellectual disability and motor and cognitive development do not seem to correlate one another.

Conclusion Surgery of associated complications can be negatively related to motor development. However, early motor development did not have any significant effects on the achievement of later cognitive functioning.
\end{abstract}

Keywords Down syndrome, Cognition, Motor development

\section{INTRODUCTION}

Down syndrome (DS) is the most common chromosomal abnormality [1-3]; it occurs in 1 per 691 babies, caused by the trisomy of chromosome 21 and associated with a characteristic phenotype in terms of physical appearance as well as with medical problems such as meta- bolic disorders, tissue dysmorphism, congenital heart disease (CHD), and thyroid dysfunction [4]. Typically, over-expression of the chromosome results in a decrease of the overall number of neurons in the central nervous system, a delay of myelination, and dysregulation of cell cycles that lead to overproduction of protein precursors and subsequently cause neurotransmission abnormali-

Received July 19, 2016; Accepted August 22, 2016

Corresponding author: Da Wa Jung

Department of Physical Medicine and Rehabilitation, National Health Insurance Service Ilsan Hospital, 100 Ilsan-ro, Ilsandong-gu, Goyang 10444, Korea. Tel: +82-31-900-0349, Fax: +82-31-900-0028, E-mail: jungdior5@gmail.com

ORCID: Hyo In Kim (http://orcid.org/0000-0003-0640-5597); Seong Woo Kim (http://orcid.org/0000-0002-1548-8147); Jiyong Kim (http://orcid. org/0000-0003-4693-8400); Ha Ra Jeon (http://orcid.org/0000-0002-4234-8086); Da Wa Jung (http://orcid.org/0000-0002-2420-3553).

(c) This is an open-access article distributed under the terms of the Creative Commons Attribution Non-Commercial License (http://creativecommons.org/ licenses/by-nc/4.0) which permits unrestricted noncommercial use, distribution, and reproduction in any medium, provided the original work is properly cited. Copyright ( 2017 by Korean Academy of Rehabilitation Medicine 
ties. Consequently, children with DS show impairment in cognitive domains such as concentration, communication, memory, and task performance compared to healthy peers [3]. Moreover, children with DS also seem to exhibit a delayed motor development due to hypotonia, ligamentous laxity, poor balance, and a lack of postural control that cause difficulties in adapting to gravity and the surrounding environment [4-6].

Most previous studies about motor development in children with DS mainly focused on gross motor skills [7-10], fine motor functions [1,11-13], and postural control $[14,15]$. A few investigations have revealed that DSafflicted children are delayed in vocabulary and cognitive development [16].

The aims of this study are to investigate motor and cognitive developmental profiles and to determine the correlation between the two areas. We hypothesize that delayed attainment of motor developmental milestones is associated with poorer cognitive function in infants with DS. In addition, we would like to assess the influencing factors of the developmental process in children with DS.

\section{MATERIALS AND METHODS}

\section{Subjects}

Among the children diagnosed with DS visiting the department of rehabilitation medicine of our clinic from March 2003 to December 2012, 78 were included in this study. They were able to follow up in an outpatient clinic until the time of independent walking. Approval to perform this retrospective study was obtained from our Institutional Review Board (IRB) and the research ethics committee.

\section{Methods}

Data such as the perinatal history and the family members' information were collected in a review of medical records. Subsequently, physical and neurological examinations were performed by a specialist of rehabilitation medicine.

- Past medical history: At the first medical examination, any possible factors that could affect to children's development were surveyed in a caregiver interview. These included neonatal seizures, feeding difficulties, sleep problems, a surgery of associated medical problems, visual or hearing impairment, and neurological issues. The most common associated problem was CHD. For analysis, we divided associated problems into three groups: CHD only, CHD with other problems, and other problems without CHD.

- Development of gross motor skills: Information was obtained about the age at which some typical motor milestones were achieved. Seven representative milestones were used: are head control, turning, sitting independently, creeping, crawling, cruising, and walking without help. Among those, the authors selected the two milestones 'head control' and 'walking independently' as the key ones to judge intra-subject severity of motor developmental delay. Of the $78 \mathrm{DS}$ children, those with an age that indicated a delay of the key milestones larger than 1 standard deviation were classified into the severe motor delay group (severe group), while others were categorized as belonging to the typical motor delay group (typical group).

- Cognitive evaluation: To determine the degree of cognitive function, the Korean Wechsler Preschool and Primary Scale of Intelligence (K-WPPSI) test was conducted between the ages 4 to 5 and the Bayley Scales of Infant Development-II (BSID-II) were conducted around 2 years of age. The subjects unable to take the K-WPPSI due to severe impairment were administered the BSID-II instead.

Using the K-WPPSI, the verbal IQ (VIQ), performance IQ (PIQ), and full-scale IQ (FIQ) were used as indexes; the mental developmental index (MDI) and psychomotor developmental index (PDI) were employed as indexes for the BSID-II. Among most children who were tested with the BSID-II, both the MDI and PDI were lower than 50, so the exact indexes could not be determined. Hence, the mental developmental quotient (MQ) and psychomotor developmental quotient (PQ) were calculated by dividing the mental or motor development age obtained from the results of BSID-II by the chronological age. Then, they were used to compare the delay rate in cognitive development between the groups.

\section{Statistical analyses}

Statistical analysis was performed using the Statistical Package for the Social Sciences (SPSS) ver. 20 for Windows (IBM SPSS Inc., Armonk, NY, USA). An independent $t$-test and the Mann-Whitney test were used to compare the means of the groups. A chi-square test was 
employed to analyze differences in motor development and cognitive functions between the two groups (severe and typical). The significance level was determines as $\mathrm{p}$ values less than 0.05 .

\section{RESULTS}

\section{Demographic data}

For children with DS, the most common reason for visiting the hospital was delayed development. The average age at the initial visit of the clinic was 8.02 months and it varied from 4 to 16 months. Thirty-one out of 78 children (39.7\%) were male.

\section{Associated problems}

Out of the 78 children, 77 (98.7\%) had associated problems and some had multiple ones. These associated problems were: 51 cases of CHD, 20 of thyroid dysfunction, 14 with a history of tube feeding, and 2 cases with intestinal problems such as an imperforate anus and a necrotizing colitis. There were 9 cases of strabismus, 5 of lacrimal duct obstruction, 1 with a cataract, 2 with a hearing impairment, 4 cases of epilepsy, and 2 cases of polydactyly.

Among the associated problems listed above, surgical treatments were required for 47 cases, $33(70.2 \%)$ of which were related to CHD (Table 1).

\section{Motor development}

The average age at which the 78 children reached each motor milestone was as follows: $6.1 \pm 2.7$ months for head control, 8.76 \pm 3.1 months for turning, $12.0 \pm 3.3$ months for sitting independently, $14.0 \pm 3.5$ months for creeping,
18.1 \pm 5.0 months for crawling, $22.3 \pm 7.2$ months for cruising, and 28.0 \pm 8.3 months for walking independently. Compared with healthy equals $[5,17,18]$, children with DS seemed to follow the same sequence of motor development, but the achievement time for all milestones was twice as long (Table 2).

Based on the age when having reached the two key milestones, the subjects were classified into severe and typical motor delay groups. In other words, children who could control their heads after 8.8 months and walk independently after 36.3 months were placed in the severe group.

\section{Cognitive development}

Forty-two out of the 78 children had taken the cognitive assessment. Out of these, 22 underwent the BSID-II test at an average age of 35.38 months (range, 23-55 months) and 20 subjects took the Wechsler tests at an average age of 54.10 months (range, 47-66 months). Comparison of the results of BSID-II test revealed that the average PQ score (43.07) was higher than the average MQ score (41.22), but the difference was not statistically significant. The average FIQ score determined by the Wechsler test 44.82 and the average VIQ score (50.88) was higher than the average PIQ score (45.76), but the result was not significant.

Correlations between the degree of associated problems and motor development

In the typical group, associated problems were evenly distributed among the three associated problems groups. In contrast, in the severe group, most cases included the 'CHD and other problems' category, but this was not sig-

Table 1. Incidence of associated problems and surgical treatments in children with Down syndrome

\begin{tabular}{|lcc}
\hline \multicolumn{1}{c}{ Medical problems } & Case & Surgical case \\
\hline Congenital heart disease & 51 & 33 \\
\hline Hyperthyroidism/hypothyroidism & 20 & 0 \\
\hline History of tube feeding & 14 & 0 \\
\hline Intestinal problem (necrotizing colitis, imperforate anus) & 2 & 2 \\
\hline Strabismus & 9 & 2 \\
\hline Lacrimal duct obstruction & 5 & 5 \\
\hline Cataract & 1 & 2 \\
\hline Hearing impairment & 2 & 0 \\
\hline Epilepsy & 4 & 1 \\
\hline Polydactyly & 2 & 2 \\
\hline
\end{tabular}


Table 2. Difference between motor milestone achievement of children with Down syndrome and healthy children (unit, month)

\begin{tabular}{lccc}
\hline & $\begin{array}{c}\text { Children with } \\
\text { down syndrome }\end{array}$ & Healthy children $^{\text {a) }}$ & $\begin{array}{c}\text { Difference between } \\
\text { the two groups }\end{array}$ \\
\hline Head control & $6.1 \pm 2.6$ & 3.0 & 3.1 \\
Turning & $8.8 \pm 3.1$ & 5.0 & 3.8 \\
Sit alone & $11.9 \pm 3.3$ & 6.0 & 5.9 \\
Creeping & $13.9 \pm 3.5$ & 8.0 & 5.9 \\
Crawling & $18.1 \pm 5.0$ & 8.5 & 9.6 \\
Cruising & $22.3 \pm 7.2$ & 9.2 & 13.1 \\
\hline Independent walking & $28.0 \pm 8.3$ & 12.1 & 15.9 \\
\hline
\end{tabular}

${ }^{\text {a) }}$ Motor milestone achievements of healthy children were defined in the references $[17,18]$.

Table 3. Correlations between the degree of associated problems, surgery, and motor development in children with Down syndrome

\begin{tabular}{lccc}
\hline & Typical group & Severe group & p-value \\
\hline CHD only & $17(34.0)$ & $7(25.0)$ & 0.356 \\
\hline CHD and other problems & $17(34.0)$ & $12(42.9)$ & \\
\hline Other problems without CHD & $15(30.0)$ & $9(32.1)$ & \\
Surgery & & & \\
Present & $30(60.0)$ & $23(82.1)$ & $0.044^{*}$ \\
\hline Absent & $20(40.0)$ & $5(17.9)$ & \\
\hline
\end{tabular}

Values are presented as number of case (\%).

CHD, congenital heart disease.

${ }^{*} \mathrm{p}<0.05$.

nificant (Table 3). Out of the 78 children, only one in the typical group did not have any medical complications.

The analysis to determine whether the surgery is related to affects motor development revealed that the number of times with any kind of surgeries was greater in the severe group than in the typical group, with the result being statistically significant $(\mathrm{p}<0.05)$. In other words, an operational history displayed negative relationship with motor development (Table 3). When motor development was scrutinized by the type of operation, there was no significant difference in motor development between the groups ( $\mathrm{p}>0.05)$.

Correlation between the degree of associated problems and cognitive development

There was no significant difference between the associated problem groups and the results of the BSID-II as well as the K-WPPSI. Comparing the cognitive assessments' results between the children with and without a history of operations, we did not find a significant differ- ence between the groups ( $p>0.05$ ) (Table 4).

Correlations between motor and cognitive development Based on the results of the BSID-II tests (22 children), the average PQ and MQ scores were calculated and compared for the severe and typical groups. The PQ scores were 44.4 and 38.6, the MQ scores were 41.8 and 39.3 in the typical and severe group, respectively; the differences were not significant $(p>0.05)$. According to the results of the K-WPPSI ( 20 children), the FIQ scores were 48.6 and 38.0, the VIQ scores 53.6 and 46.0, and the PIQ scores 50.0 and 38.2 in the typical and severe group, respectively. The FIQ, VIQ and PIQ scores were all higher in the typical group than in the severe group, but the differences were not significant (Table 5).

\section{DISCUSSION}

There have been several studies about the motor and cognitive development of DS children, but the results 
Table 4. Correlations among the degree of associated problems, operational history, and cognitive development in children with Down syndrome

\begin{tabular}{|c|c|c|c|c|c|c|c|}
\hline & \multirow{2}{*}{ CHD only } & \multirow{2}{*}{$\begin{array}{l}\text { CHD and other } \\
\text { problems }\end{array}$} & \multirow{2}{*}{$\begin{array}{l}\text { Other problems } \\
\text { without } \mathrm{CHD}\end{array}$} & \multirow{2}{*}{ p-value } & \multicolumn{2}{|c|}{ Operational history } & \multirow{2}{*}{ p-value } \\
\hline & & & & & Present & Absent & \\
\hline \multicolumn{8}{|c|}{ BSID-II } \\
\hline PQ & 49.3 & 38.9 & 45.4 & 0.385 & 42.4 & 38.9 & 0.783 \\
\hline MQ & 48.9 & 40.1 & 38.8 & 0.451 & 43.0 & 43.2 & 0.731 \\
\hline \multicolumn{8}{|c|}{ K-WPPSI } \\
\hline FIQ & 59.0 & 39.5 & 48.4 & 0.298 & 45.6 & 43.5 & 0.725 \\
\hline PIQ & 51.0 & 44.1 & 50.0 & 0.506 & 45.0 & 47.0 & 0.919 \\
\hline VIQ & 55.0 & 46.9 & 54.4 & 0.181 & 50.7 & 51.1 & 0.959 \\
\hline
\end{tabular}

CHD, congenital heart disease; BSID-II, Bayley Scales of Infant Development-II; PQ, psychomotor developmental quotient; MQ, mental developmental quotient; K-WPPSI, Korean Wechsler Preschool and Primary Scale of Intelligence; FIQ, full-scale intelligence quotient; PIQ, performance intelligence quotient; VIQ, verbal intelligence quotient.

Table 5. Correlations between motor and cognitive development in children with Down syndrome

\begin{tabular}{cccc}
\hline & Typical group & Severe group & p-value \\
\hline BSID-II & & & \\
\hline PQ & 44.4 & 38.6 & 0.756 \\
\hline MQ & 41.8 & 39.3 & 0.945 \\
K-WPPSI & & & \\
\hline FIQ & 48.6 & 38.0 & 0.104 \\
VIQ & 53.6 & 46.0 & 0.829 \\
\hline PIQ & 50.0 & 38.2 & 0.222 \\
\hline
\end{tabular}

BSID-II, Bayley Scales of Infant Development-II; PQ, psychomotor developmental quotient; MQ, mental developmental quotient; K-WPPSI, Korean Wechsler Preschool and Primary Scale of Intelligence; FIQ, full-scale intelligence quotient; PIQ, performance intelligence quotient; VIQ, verbal intelligence quotient.

varied. Many of them have categorized age according to the achievement of certain motor skills. Because the results have been based on wide age ranges, the age at which certain motor skills are achieved has been a controversial issue among researchers. According to Melyn and White [19] and Fishler et al. [20], motor development in children with DS has been depicted as follows: they can sit without support after 14 months since birth, crawl after 12-18 months, and walk independently after 24-74 months. In DS, $40 \%-44 \%$ are able to walk without support before the age of two years, and $78 \%-90 \%$ of the children could walk independently before the age of three. In the present study, the average age of children who reached the turning and independent sitting milestones was 8.76 and 11.87 months, respectively, which was in accordance with a previous study $[21,22,24]$. The average age of children who achieved the ability to walk independently was 25.04 months, which was also similar to prior investigations $[23,24]$. We found that children with DS needed twice the time than healthy peers to attain motor skills.

It was reported that $44 \%-56 \%$ of children with DS had CHD $[25,26]$, but we found $65.4 \%$. In another study [27], children with CHD only exhibited a difference in the motor domain of neurological development compared to those without CHD. However, we could not find any difference of motor development with or without the presence of CHD.

We found that having any kinds of operation might have some negative relationship with the motor development in children with DS. During the first 24 months after birth, brain development is processed by the experience dependent fashion and receiving external stimuli is crucial at this age [28]. Thus, undergoing an operation during this period at least results in a longer hospital stay and activity restrictions, which limit the child's exposure to external stimuli and inhibits brain development. Consequently, the achievement of motor milestones is delayed. According to van Trotsenburg et al. [29], infants with DS who had a hospital stay longer than 11 days showed a significant delay in mental development compared to those with shorter stays. In the present study, information about the length of stay could not be obtained. The degree of intellectual disability defined as an average FIQ of the Wechsler test in this study, was in the moderately retarded range. Gibson [30] documented that the 
IQ in DS is usually in the moderately to severely retarded range which is consistent with our study. In addition, children who underwent the Wechsler tests did not show a discrepancy between their verbal and nonverbal intelligence development. This is not consistent with previous results: Tsao and Kindelberger [31] reported that children with DS 6-10 years old achieved better scores in nonverbal tests, including visuomotor processing than verbal tests when they used the Differential Scales of Intellectual Efficiency [32] for the assessment of cognitive development. The average age of children included in the present study was lower which might account for the difference.

In the present study, we compared the cognitive and motor development and could not find a statistically significant correlation between the achievement of motor milestones and cognitive functions. Seitz et al. [33] reported that motor deficits in children who weighed $<1,250 \mathrm{~g}$ at birth without severe disabilities correlated with cognitive impairment, especially in the visuomotor domain. Joo et al. [34] revealed that late walkers had a significantly lower cognition and social adaptive function scores than early walkers among children with a history of preterm birth, but without major neurodevelopmental impairments. However, in children with DS, there was no significant correlation between early motor development and later cognitive function.

This study is limited because it was conducted at a single institution with a small sample. Further studies, including larger populations and long-term follow-ups, are needed to investigate cognitive development in DS.

In conclusion, children with DS followed the same motor development sequence and generally took the twice the time for reaching gross motor developmental milestones compared to healthy equals. Furthermore, having a surgery of associated complications was related to a higher frequency of delayed motor development. But such early motor development did not have any significant effects on the achievement of later cognitive functions. The results of the present study may be helpful to understand the natural course of children's development with DS and implement an appropriate intervention according to developmental stages.

\section{CONFLICT OF INTEREST}

No potential conflict of interest relevant to this article was reported.

\section{REFERENCES}

1. Frank K, Esbensen AJ. Fine motor and self-care milestones for individuals with Down syndrome using a Retrospective Chart Review. J Intellect Disabil Res 2015;59:719-29.

2. Parker SE, Mai CT, Canfield MA, Rickard R, Wang Y, Meyer RE, et al. Updated National Birth Prevalence estimates for selected birth defects in the United States, 2004-2006. Birth Defects Res A Clin Mol Teratol 2010;88:1008-16.

3. Weijerman ME, de Winter JP. Clinical practice: the care of children with Down syndrome. Eur J Pediatr 2010;169:1445-52.

4. Pangalos C, Avramopoulos D, Blouin JL, Raoul O, deBlois MC, Prieur M, et al. Understanding the mechanism(s) of mosaic trisomy 21 by using DNA polymorphism analysis. Am J Hum Genet 1994;54:47381.

5. Ulrich DA, Lloyd MC, Tiernan CW, Looper JE, AnguloBarroso RM. Effects of intensity of treadmill training on developmental outcomes and stepping in infants with Down syndrome: a randomized trial. Phys Ther 2008;88:114-22.

6. Palisano RJ, Walter SD, Russell DJ, Rosenbaum PL, Gemus M, Galuppi BE, et al. Gross motor function of children with down syndrome: creation of motor growth curves. Arch Phys Med Rehabil 2001;82:494500.

7. Malak R, Kotwicka M, Krawczyk-Wasielewska A, Mojs E, Samborski W. Motor skills, cognitive development and balance functions of children with Down syndrome. Ann Agric Environ Med 2013;20:803-6.

8. Edgin JO. Cognition in Down syndrome: a developmental cognitive neuroscience perspective. Wiley Interdiscip Rev Cogn Sci 2013;4:307-17.

9. Martin K. Effects of supramalleolar orthoses on postural stability in children with Down syndrome. Dev Med Child Neurol 2004;46:406-11.

10. Mauerberg-deCastro E, Angulo-Kinzler RM. Locomotor patterns of individuals with Down syndrome: effects of environmental and task constraints. In: Weeks DJ, Chua R, Elliott D, editors. Perceptual-motor behavior in Down syndrome. Champaign: Human Ki- 
netics; 2000. p. 71-98.

11. de Campos AC, Rocha NA, Savelsbergh GJ. Development of reaching and grasping skills in infants with Down syndrome. Res Dev Disabil 2010;31:70-80.

12. Charlton JL, Ihsen E, Oxley J. Kinematic characteristics of reaching in children with Down syndrome. Hum Mov Sci 1996;15:727-43.

13. Frank K, Esbensen AJ. Fine motor and self-care milestones for individuals with Down syndrome using a Retrospective Chart Review. J Intellect Disabil Res 2015;59:719-29.

14. Polastri PF, Barela JA. Perception-action coupling in infants with Down syndrome: effects of experience and practice. Adapt Phys Activ Q 2005;22:39-56.

15. Polastri PF, Barela JA. Visual information and trunk sway coupling in infants with Down syndrome. J Sport Exerc Psychol 2002;24:104.

16. Cicchetti D, Beeghly M. Children with Down syndrome: a developmental perspective. New York: Cambridge University Press; 1990. p. 280-313.

17. WHO Multicentre Growth Reference Study Group. WHO Motor Development Study: windows of achievement for six gross motor development milestones. Acta Paediatr Suppl 2006;450:86-95.

18. Alexander MA, Matthews DJ, Murphy KP. Pediatric rehabilitation: principles and practice. 5 th ed. New York: Demos Medical Publishing; 2015.

19. Melyn MA, White DT. Mental and developmental milestones of noninstitutionalized Down's syndrome children. Pediatrics 1973;52:542-5.

20. Fishler K, Share J, Koch R. Adaptation of Gesell developmental scales for evaluation of development in children with Down's syndrome (Mongolism). Am J Ment Defic 1964;68:642-6.

21. Centerwall SA, Centerwall WR. A study of children with mongolism reared in the home compared to those reared away from the home. Pediatrics 1960;25:678-85.

22. Kugel RB, Reque D. A comparison of mongoloid children. JAMA 1961;175:959-61.

23. Jobling AA, Virji-Babul N. Motor development in Down syndrome: play, move and grow. Burnaby: Down syndrome Research Foundation; 2004. p. 15-22. 24. Babb JG. Gross motor skills in children with Down syndrome. J Dev Behav Pediatr 2000;21:155-6.

25. Tudella E, Pereira K, Basso RP, Savelsbergh GJ. Description of the motor development of 3-12 month old infants with Down syndrome: the influence of the postural body position. Res Dev Disabil 2011;32:151420.

26. Alsaied T, Marino BS, Esbensen AJ, Anixt JS, Epstein JN, Cnota JF. Does congenital heart disease affect neurodevelopmental outcomes in children with Down syndrome? Congenit Heart Dis 2016;11:26-33.

27. Tapp S, Anderson T, Visootsak J. Neurodevelopmental outcomes in children with Down syndrome and infantile spasms. J Pediatr Neurol 2015;13:74-7.

28. Gallagher A, Dagenais L, Doussau A, Décarie JC, Materassi M, Gagnon K, et al. Significant motor improvement in an infant with congenital heart disease and a rolandic stroke: the impact of early intervention. Dev Neurorehabil 2016 Feb 18 [Epub]. http://dx.doi.org/10. 3109/17518423.2015.1132280

29. van Trotsenburg AS, Heymans HS, Tijssen JG, de Vijlder JJ, Vulsma T. Comorbidity, hospitalization, and medication use and their influence on mental and motor development of young infants with Down syndrome. Pediatrics 2006;118:1633-9.

30. Gibson D. Down's syndrome: the psychology of mongolism. New York: Cambridge University Press; 1978.

31. Tsao R, Kindelberger C. Variability of cognitive development in children with Down syndrome: relevance of good reasons for using the cluster procedure. Res Dev Disabil 2009;30:426-32.

32. Perron-Borelli M, Perron R. Differential Scales of Intellectual Efficiency [Echelles differentielles d'efficiences intellectuelles]. Paris: Ets d'Applications Psychotechniques; 1996.

33. Seitz J, Jenni OG, Molinari L, Caflisch J, Largo RH, Latal Hajnal B. Correlations between motor performance and cognitive functions in children born $<1250$ $\mathrm{g}$ at school age. Neuropediatrics 2006;37:6-12.

34. Joo JW, Choi JY, Rha DW, Kwak EH, Park ES. Neuropsychological outcomes of preterm birth in children with no major neurodevelopmental impairments in early life. Ann Rehabil Med 2015;39:676-85. 